\title{
Penyuluhan dan Pembuatan Settling Pond dalam Upaya Pengurangan Pencemaran Limbah Tambang
}

\author{
Baiq Rina Amalia Safitri*, Sukainil Ahzan, Pahriah, Mina Yuliana, Husnul Heni Martina, \\ Reni Satpiri
}

Universitas Pendidikan Mandalika, Jl. Pemuda No. 59A, Mataram, 83125 Indonesia

${ }^{*}$ Corresponding author email: bqrinaamaliasafitri@ikipmataram.ac.id

\section{Diterima: Agustus 2019; Revisi: Oktober 2019; Diterbitkan: November 2019}

\begin{abstract}
Abstrak
Berdasarkan hasil pengujian di laboratorium penguji Balai Pengkajin Teknologi Pertanian (BPTP) NTB bahwa batuan tambang yang ada di daerah Sekotong tidak hanya mengandung emas tetapi terdapat beberapa kandungan mineral lainnya seperti $\mathrm{P}, \mathrm{Zn}, \mathrm{Fe}, \mathrm{Cu}, \mathrm{Al}$, dan $\mathrm{S}$, metode yang digunakan dengan AAS (Atomic Absorption Spectrophotometry). Logam berat Fe merupakan logam berat essensial yang keberadaannya dalam jumlah tertentu sangat dibutuhkan oleh organisme hidup, namun dalam jumlah yang berlebih dapat menimbulkan efek racun. Untuk mengatasi masalah maka melakukan dua kegiatan yakni: a) penyuluhan tentang pentingnya kebersihan terhadap lingkungan. b) pembuatan saluran limbah agar tidak mencemari lingkungan yakni pembuatan kolam pengendapan (settling pond). Selain itu dari kolam pengendapan (settling pond) didapat lumpur dari sisa pengolahan atau penggelondongan emas, lumpur tersebut dapat dimanfaatkan menjadi barang bernilai ekonomi dan memiliki harga jual seperti bata tanpa bakar. Hasil dari kegiatan yang dilakukan yaitu pengetahuan masyarakat penambang tentang pentingnya lingkungan yang bersih dan kolam pengendapan (settling pond) dan kemampuan masyarakat tambang dalam mengolah limbah menjadi barang bernilai jual yaitu dengan membuat bata tanpa bakar. Keberhasilan dari kegiatan ini terlihat dari banyaknya masyarakat yang hadir dan antusiasnya mereka dalam mendukung kegiatan ini yakni dengan terjun langung membantu
\end{abstract}

Kata Kunci: limbah; kolam pengendapan; kebersihan lingkungan

\section{Counseling and Making Settling Pond in an Effort to Reduce Mine Waste Pollution}

\begin{abstract}
Based on the test results at the NTB Agricultural Technology Center (BPTP) examiner laboratory that mining rocks in the Sekotong area not only contain gold but there are several other mineral contents such as $P, \mathrm{Zn}, \mathrm{Fe}, \mathrm{Cu}, \mathrm{Al}$, and $\mathrm{S}$, the method used with AAS (Atomic Absorption Spectrophotometry). Heavy metal $\mathrm{Fe}$ is an essential heavy metal whose existence in a certain amount is needed by living organisms, but in excessive amounts can cause toxic effects. To overcome the problem, two activities are carried out, namely: a) counseling about the importance of cleanliness to the environment. b) making sewage lines so as not to pollute the environment, namely the creation of settling ponds. Besides that, from settling ponds, sludge is obtained from the processing waste or gold rolling, the sludge can be utilized as economic value goods and has a selling price such as brick without burning. The results of the activities carried out are the knowledge of the mining community about the importance of a clean environment and settling ponds and the ability of the mining community to process waste into valuable goods, by making bricks without burning. The success of this activity can be seen from the large number of people present and their enthusiasm in supporting this activity by jumping in to help.
\end{abstract}

Keywords: writing waste; sedimentation ponds; environmental hygiene

How to Cite: Safitri, B., Ahzan, S., Pahriah, P., Yuliana, M., Martina, H., \& Satpiri, R. (2019). Penyuluhan dan Pembuatan Settling Pond dalam Upaya Pengurangan Pencemaran Limbah Tambang. Lumbung Inovasi: Jurnal Pengabdian kepada Masyarakat, 4(2), 50-55. doi:https://doi.org/10.36312/linov.v4i2.454 


\section{PENDAHULUAN}

Kecamatan Sekotong adalah kecamatan paling selatan dari Kabupaten Lombok Barat dan berbatasan langsung dengan Samudera Hindia. Daerah ini diketahui mengandung emas dengan kandungan yang cukup berarti. Daerah Sekotong pernah dieksplorasi oleh PT. NNT sejak tahun 1986 hingga tahun 2004, akan tetapi PT. NNT menilai bahwa potensi emas yang ada rendah, sehingga diserahkan kembali kepada pemerintah propinsi NTB. Selanjutnya penambangan diambil alih oleh PT. Indotan setelah memperoleh kuasa pertambangan dari pemerintah. Setelah keluarnya Peraturan Daerah tentang Rencana Tata Ruang Wilayah (RTRW) nomor 11 tahun 2006, PT. Indotan menghentikan kegiatan eksplorasinya. Selanjutnya sejak awal tahun 2008 aktivitas penambangan dilakukan oleh masyarakat atau yang disebut Penambangan Tanpa ljin (PETI) (Sancayaningsih dkk. 2010).

Aktivitas penambangan tampa ijin masyarakat terus terjadi tentunya hal tersebut dapat mengacam atau berdampak pada pencemaran lingkungan dan laut sekitar. Proses aktivitas penambangan tradisional ini menggunakan teknik sederhana dan murah, tanpa memperhatikan aspek keselamatan lingkungan akibat pencemaran limbah tilling. Proses pengolahan emas menggunakan teknik amalgamasi, yaitu dengan mencampur batuan dengan merkuri (Air raksa atau $\mathrm{Hg}$ ) dalam media air menggunakan alat gelondong untuk membentuk amalgam (logam paduan $\mathrm{Au}-\mathrm{Hg}$ ). Biji atau pulp yang telah digelondong disaring dan diperas dengan kain parasit untuk memisahkan amalgam terhadap ampasnya. Selanjutnya, emas dipisahkan dengan proses penggarangan (penguapan merkuri) pada suhu 400 OC di tempat terbuka.

Kelompok sadar wisata (Pokdarwis) yang ada di daerah Sekotong mengkhawatirkan aktivitas pertambangan ilegal yang masih terjadi di kawasan Sekotong khususnya di daerah wisata akan mengancam pariwisata Sekotong ke depan. Pasalnya, aktivitas ini dikhawatirkan berdampak pada pecemaran lingkungan dan laut sekitar. Sementara sejauh ini pemda belum mampu mengawinkan atara pariwisata dengan pertambangan, lantaran programnya terkesan berjalan sendiri-sendiri.

Hal ini disampaikan Ketua Pokdarwis Gili Gede Kecamatan Sekotong, Menurutnya, sejauh ini pemda belum mampu memadukan antara pertambangan dengan pariwisata sesuai kebijakan yang ditetapkan di Sekotong. "Terkesan di lapangan antara dua sektor yang diharapkan berdampingan ini berjalan sendiri-sendiri. Selanjutnya ketua Pokdarwis menyatakan juga kurang setuju jika ada perusahaan ingin mengeksploitasi tambang di Sekotong, karena ujung-ujungnya masyarakat setempat akan rugi.

Hasil wawancara dengan Kepala Desa Buwun Mas mengatakan, aktivitas tambang digeluti warganya sejak akhir 2008 silam. Diakui jumlah warganya yang menjadi penambang lumayan banyak. Namun secara data riil ia belum kalikan pendataan. "Tambang ini bukan mata pencaharian utama, sebab mereka punya pekerjaan tetap jadi petani, peternak dan nelayan," tegasnya. Diakui, warganya akan menjadi penambang liar ketika ada informasi lubang cair, karena mereka tergiur dengan cepatnya memperoleh uang dari penambangan emas.

Berdasarkan dari data di lapangan bahwa yang menjadi penambang ilegal banyak sehingga aktivitas ini dikhawatirkan berdampak pada pecemaran lingkungan dan laut sekitar. Dimana, dari mulai penambangan sampai pengolahan batu tambang tersebut agar mendapatkan emas masih dilakukan dengan cara tradisional, seperti terlihat pada Gambar 1 di bawah ini.

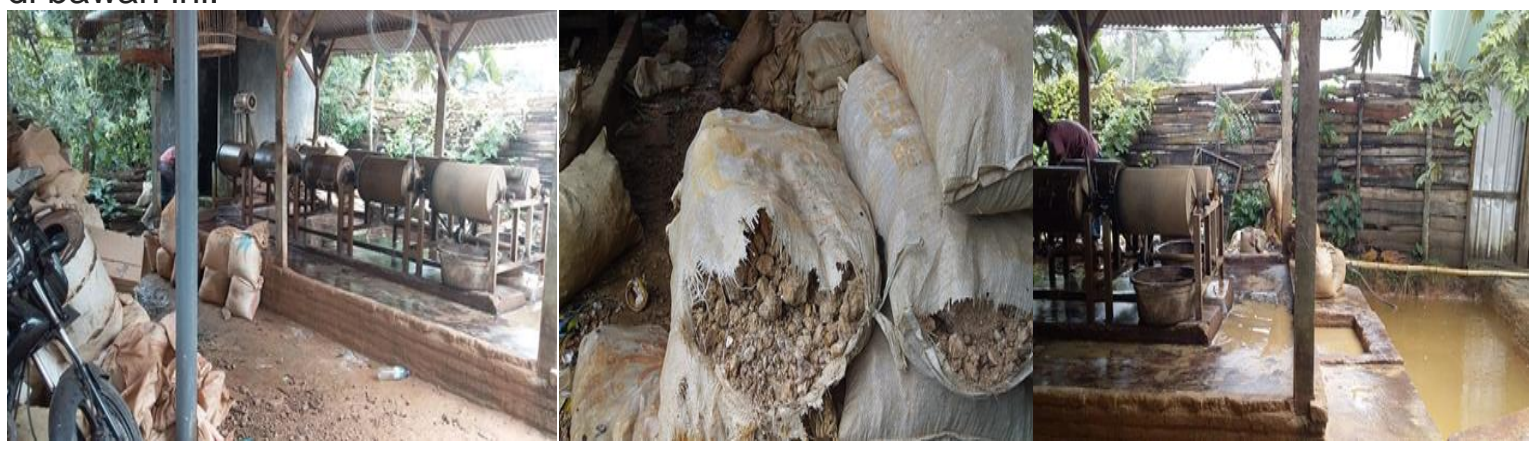

Gambar 1. Pengolahan Batu untuk mendapatkan Emas (Sumber: Dokumentasi kegiatan) 
Air sisa pengolahan emas secara tradisional ini akan mengalir ke sungai melewati saluran irigasi yang akan mencemari lingkungan dan air sekitar. Untuk itu kami mengadakan penyuluhan tentang bahaya air yang sudah tercampur dengan sisa pengolahan emas tersebut.

Berdasarkan hasil pengujian di laboratorium penguji Balai Pengkajian Teknologi Pertanian (BPTP) NTB bahwa batuan tambang yang ada di daerah sekotong tidak hanya mengandung emas tetapi terdapat beberapa kandungan mineral lainnya seperti $\mathrm{P}, \mathrm{Zn}, \mathrm{Fe}$, $\mathrm{Cu}, \mathrm{Al}$, dan S, metode yang digunakan dengan AAS (Atomic Absorption Spectrophotometry). Dari hasil pengujian terdapat nilai Fe terbesar dibanding yang lain (Sofyan, 20 Juni 2019). Logam berat Fe merupakan logam berat essensial yang keberadaannya dalam jumlah tertentu sangat dibutuhkan oleh organisme hidup, namun dalam jumlah yang berlebih dapat menimbulkan efek racun (Supriyantini \& Endrawati, Juni 2015)

\section{METODE PELAKSANAAN}

Program pengabdian kepada masyarakat yang diusulkan ini akan dilakukan dengan menggunakan pola sekolah lapang (Safitri dkk, 2018). Pola sekolah lapang akan memberikan titik tekan pada eksplorasi pengetahuan, kesadaran terhadap lingkungan, dan keterampilan.

Pola sekolah lapang akan memberikan titik tekan pada eksplorasi pengetahuan, kesadaran terhadap lingkungan, dan keterampilan. Dalam pembuatan bata tanpa bakar ini akan digunakan metode pendidikan orang dewasa (POD) agar masyarakat di Taman Ayu merasa nyaman, senang, akrab, dan tercipta suasana kesetaraan sehingga materi yang disampaikan dapat terserap secara maksimal. Pendidikan Orang Dewasa yang akan dilakukan mengacu pada skema yang terlihat pada Gambar 2 di bawah ini (Suprijanto, 2006).

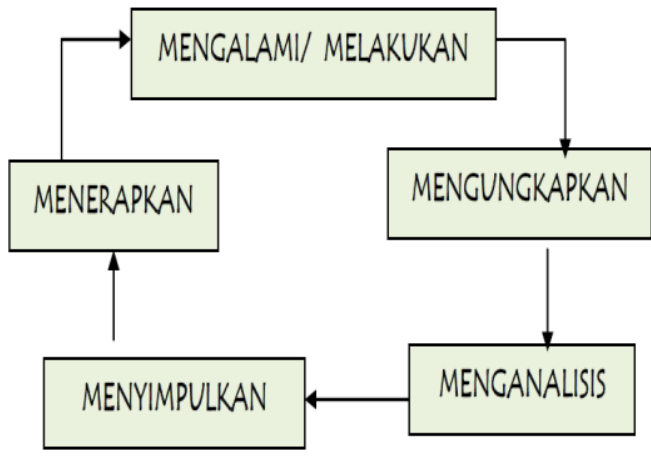

Gambar 2. Daur Belajar Orang Dewasa

Persiapan kegiatan meliputi mekanisme pelaksanaan kegiatan yaitu sebelum terjun ke lapangan, maka perlu dilakukan beberapa hal sebagai bentuk persiapan, antara lain: a) melakukan pendataan dan verifikasi masyarakat penambang, b) sosialisasi program kepada masyarakat penambang di Sekotong terkait rencana program pengabdian dan karakteristik masyarakat penambang setempat yang akan dilibatkan dalam pelaksanaan program kerja.

Materi yang akan disampaikan kepada masyarakat penambang dalam kepedulian terhadap kebersihan lingkungan antara lain: a) menyiapkan materi tentang pentingnya kebersihan terhadap lingkungan. b) memberikan contoh pembuatan saluran limbah agar tidak mencemari lingkungan yakni menurut (Husain, 2016) pembuatan kolam pengendapan (settling pond).

\section{HASIL DAN PEMBAHASAN}

Kegiatan ini dilaksanakan pada tanggal 1 April 2019 sampai 7 April 2019 di desa Sekotong. Bentuk kegiatan ini adalah penyuluhan kebersihan terhadap lingkungan dan memberikan contoh pembuatan saluran limbah agar tidak mencemari lingkungan. Manfaat dari kegiatan ini adalah terciptanya lingkungan yang bersih. Peserta dalam kegiatan ini adalah mayarakat penambang. Fasilitator dalam kegiatan ini adalah dosen dan mahasiswa IKIP Mataram yang mengajar di program studi pendidikan Fisika fakultas pendidikan Matematika dan Ilmu Pengetahuan Alam. 
Seluruh peserta diharapkan akan mendapatkan materi dalam 2 (dua) kategori yaitu materi yang akan disampaikan kepada masyarakat penambang dalam kegiatan ini antara lain: a) pentingnya lingkungan yang bersih. b) menyiapkan alat dan bahan untuk membuat saluran limbah agar tidak mencemari lingkungan.

Pola sekolah lapang akan memberikan titik tekan pada eksplorasi pengetahuan, kesadaran terhadap lingkungan, dan keterampilan. Dalam pembuatan bata tanpa bakar ini akan digunakan metode pendidikan orang dewasa (POD) agar masyarakat di desa Sekotong merasa nyaman, senang, akrab, dan tercipta suasana kesetaraan sehingga materi yang disampaikan dapat terserap secara maksimal.

Pertama-tama membagikan materi berupa hard copy tentang pentingnya kebersihan terhadap lingkungan kepada para peserta penyuluhan. Penyampaian materi penyuluhan menggunakan Laptop dan LCD, supaya para peserta dapat melihat langsung sehingga para peserta dapat menanyakan secara langsung apabila ada kesulitan. Pembuatan kolam pengendapan (settling pond), seperti pada Gambar 3 di bawah ini.

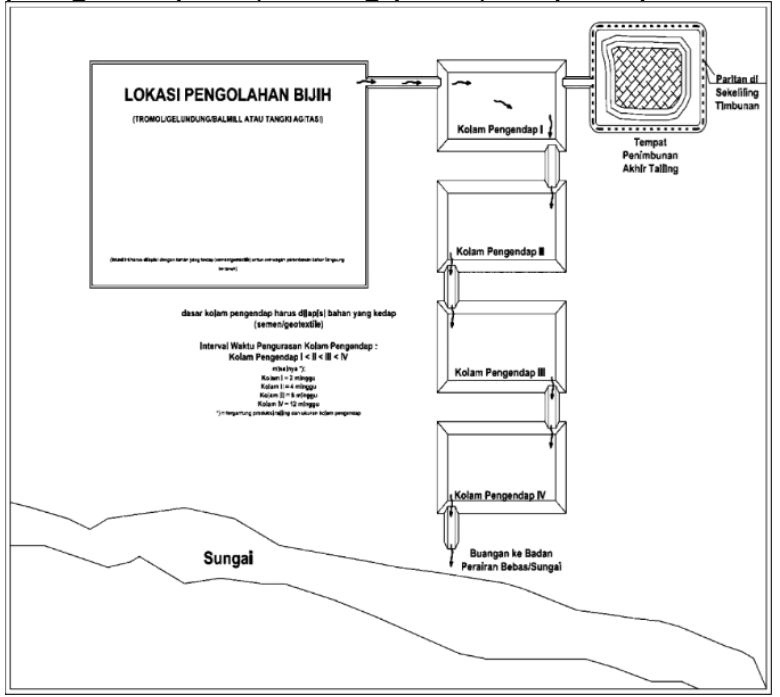

Gambar 3. Konstruksi Kolam Pengendap (Sumber: Menlh, Peraturan Menlh No 23 Tahun 2008 Tentang Pedoman Teknis Pencegahan Dana/Atau Kerusakan Lingkungan Hidup Akibat Pertambangan Emas Rakyat, 2008)

Ekstraksi yang baik yaitu: a). lokasi ekstraksi bijih harus terpisah dari lokasi kegiatan penambangan. b). dilakukan pada lokasi khusus baik untuk amalgamasi ataupun sianidasi untuk meminimalkan penyebab pencemar bahan berbahaya akibat peresapan kedalam tanah, terbawa aliran air permukaan maupun gas yang terbawa oleh angin. c) dilengkapi dengan kolam pengendap yang berfungsi baik untuk mengolah seluruh tailing hasil pengolahan sebelum dialirkan ke perairan bebas. d) lokasi pengolahan bijih dan kolam pengendap diusahakan tidak berada pada daerah banjir. Sebagai panduan, perhitungan sederhana kebutuhan kolam pengendapan dilokasi pengolahan sebagai berikut: luas kolam pengendap $I\left(\mathrm{~m}^{2}\right)=20 \times$ volume tailing yang dihasilkan setiap proses $\left(\mathrm{m}^{3}\right)$. Asumsi : 1$)$. kedalaman kolam $=2 \mathrm{~m}$. 2). ukuran luas kolam pengendap II dapat lebih kecil dari kolam II (minimal $0.5 \mathrm{x}$ luas kolam I). Perkiraan Interval waktu pengerukan terutama untuk kolam pertama $($ hari $)=\left(\right.$ volume kolam pengendap I) $/$ volume tailing $/$ hari $\left(\mathrm{m}^{3} / \mathrm{hari}\right)$

Catatan: Kedalaman air pada titik keluaran minimal $0.5 \mathrm{~m}$, kurang dari nilai tersebut kolam pengendap harus dikosongkan untuk menjaga kinerja pengendapan kolam tersebut. Contoh Perhitungan.

\begin{tabular}{lcl}
\hline Volume tailing per proses & 1.6 & $\mathrm{~m}^{3}$ \\
\hline Waktu proses & $8-12$ & jam \\
\hline Luas kolam pengendap & 32 & $\mathrm{~m}^{2}$ \\
\hline Kedalaman kolam pengendap & 2 & $\mathrm{~m}$ \\
\hline Kapasitas kolam pengendap & 48 & $\mathrm{~m}^{3}$ \\
\hline Perkiraan waktu pengurasan & 30 & proses \\
\hline
\end{tabular}


kolam pengendap, (asumsi waktu operasi 15 hari

8 jam/proses dan $2 \times$ proses per hari)

Ekstraksi yang baik yaitu: a). lokasi ekstraksi bijih harus terpisah dari lokasi kegiatan penambangan. b). dilakukan pada lokasi khusus baik untuk amalgamasi ataupun sianidasi untuk meminimalkan penyebab pencemar bahan berbahaya akibat peresapan kedalam tanah, terbawa aliran air permukaan maupun gas yang terbawa oleh angin. c) dilengkapi dengan kolam pengendap yang berfungsi baik untuk mengolah seluruh tailing hasil pengolahan sebelum dialirkan ke perairan bebas. d) lokasi pengolahan bijih dan kolam pengendap diusahakan tidak berada pada daerah banjir. Sebagai panduan, perhitungan sederhana kebutuhan kolam pengendapan dilokasi pengolahan sebagai berikut: luas kolam pengendap $I\left(\mathrm{~m}^{2}\right)=20 \mathrm{x}$ volume tailing yang dihasilkan setiap proses $\left(\mathrm{m}^{3}\right)$. Asumsi : 1$)$. kedalaman kolam $=2 \mathrm{~m}$. 2). ukuran luas kolam pengendap II dapat lebih kecil dari kolam II (minimal $0.5 \times$ luas kolam I). Perkiraan Interval waktu pengerukan terutama untuk kolam pertama (hari) $=$ (volume kolam pengendap I)/[volume tailing/hari $\left(\mathrm{m}^{3} /\right.$ hari $)$, e) gunakan merkuri dan sianida secukupnya, f) bahan kimia ditempatkan pada ruangan tersendiri, dan $\mathrm{g}$ ) menggunakan perlengkapan yang mendukung keselamatan dan kesehatan kerja. Hal ini sesuai dengan aturan pemerintah yaitu (Menlh, Peraturan Menlh No 23 Tahun 2008 Tentang Pedoman Teknis Pencegahan Dana/Atau Kerusakan Lingkungan Hidup Akibat Pertambangan Emas Rakyat, 2008).

Catatan : Kedalaman air pada titik keluaran minimal $0.5 \mathrm{~m}$, kurang dari nilai tersebut kolam pengendap harus dikosongkan untuk menjaga kinerja pengendapan kolam tersebut.

Contoh Perhitungan :

\begin{tabular}{llcl}
\hline Volume tailing per proses & $:$ & 1.6 & $\mathrm{~m}^{3}$ \\
\hline Waktu proses & $:$ & $8-12$ & jam \\
Luas kolam pengendap & $:$ & 32 & $\mathrm{~m}^{2}$ \\
\hline Kedalaman kolam pengendap & $:$ & 2 & $\mathrm{~m}$ \\
\hline Kapasitas kolam pengendap & $:$ & 48 & $\mathrm{~m}^{3}$ \\
\hline Perkiraan waktu pengurasan & $:$ & 30 & proses \\
\hline kolam pengendap, (asumsi waktu operasi & $:$ & 15 & hari
\end{tabular}

8 jam/proses dan $2 \times$ proses per hari)

Hasil dari kegiatan yang dilakukan yaitu pengetahuan masyarakat penambang tentang pentingnya lingkungan yang bersih dan kolam pengendapan (settling pond). Menurut (MENLH, 10 Juli 3002) Setiap penanggung jawab usaha dan atau kegiatan pertambangan emas atau batu bara wajib mengelola air yang terkena dampak dari kegiatan penambangan melalui kolam pengendapan (pond). Selain itu dari kolam pengendapan (settling pond) didapat lumpur dari sisa pengolahan atau penggelondongan emas, lumpur tersebut dapat dimanfaatkan menjadi barang bernilai ekonomi dan memiliki harga jual seperti bata tanpa bakar. Keberhasilan dari kegiatan ini terlihat dari banyaknya masyarakat yang hadir dan antusiasnya mereka dalam mendukung kegiatan ini yakni dengan terjun langung membantu.

\section{KESIMPULAN}

Berdasarkan pada hasil kegiatan dapat disimpulkan bahwa pengetahuan masyarakat penambang tentang pentingnya lingkungan yang bersih dan kolam pengendapan (settling pond) kemampuan masyarakat tambang dalam mengolah limbah menjadi barang bernilai jual yaitu dengan membuat bata tanpa bakar, sehingga tercipta pengurangan pencemaran limbah tambang terhadap lingkungan sekitar.

\section{DAFTAR PUSTAKA}

Redaksi, S. N. (2019). Pemda Dinilai Belum Mampu "Kawinkan" Pertambangan dan Pariwisata Sekotong. Mataram: SUARA NTB.

Redaksi, S. N. (25 April 2019). Tambang dan Pariwisata Sekotong bisa dikawinkan. Mataram: SUARA NTB. 
Safitri, B. R., P, D. S., Sukroyanti, B. A., Putrayadi, W., Prayogi, S., \& Ahmadi. (Oktober 2018). Pelatihan Pembuatan Bata Tanpa Bakar Berbahan Dasar Limbah Batu Bara di Desa Taman Ayu. Lumbung Inovasi, Vol 3 (1): 17-19 e-ISSN:2541-626X .

Sofyan, A. (20 Juni 2019). Laporan Hasil Pengujian Batuan . Mataram: Laboratorium Penguji Balai Pengkajian Teknologi Pertanian (BPTP) NTB.

Suprijanto. (2006). Pendidikan Orang Dewasa. Jakarta: Bumi Aksara.

Supriyantini, E., \& Endrawati, H. (Juni 2015). Kandungan Logam Berat Besi (Fe) Pada Air, Sedimen, dan Kerang Hijau (Perna Viridis) di Perairan Tanjung Emas Semarang. Jurnal Kelautan Tropis, Vol 18 (1): 38-45.

Sancayaningsih P.R., Sutariningsih E., Hadisusanto S., Purnomo, Mulyati, Sembiring L, \& Sudibyo P (2010) Studi Kandungan Merkuri Pada Pertambangan Emas Tradisional Di Kecamatan Sekotong, Lombok Barat. Tim Peneliti Sekotong. Fakultas biologi UGM. https://repository.ugm.ac.id/135805/1/llaporan\%20\%20sekotong\%201.pdf 